\title{
Shortening the Period for Assessing the Resistance of Olive to Verticillium Wilt Using Continuous Lighting
}

\author{
Gloria María García-Ruiz ${ }^{1}$ \\ IFAPA (Instituto de Investigación y Formación Agraria y Pesquera), Centro \\ 'Alameda del Obispo', 14080 Córdoba, Spain
}

Carlos Trapero and Francisco Javier López-Escudero

Departamento de Agronomía, Universidad de Córdoba-Campus de Excelencia Internacional Agroalimentario CeiA3, Campus Universitario de Rabanales, Edificio Celestino Mutis (C4), 14071, Córdoba, Spain

Additional index words. defoliating pathotype, olive breeding program, photoperiod, root-dip inoculation, Verticillium dahliae

\begin{abstract}
The use of continuous and natural lighting was studied to assess the resistance of 12 olive cultivars to the defoliating pathotype of Verticillium dahliae. The plants were inoculated by dipping their bare root system in a conidial suspension. 'Frantoio' was used as a moderately resistant control cultivar. Several evaluated cultivars were susceptible to the defoliating pathotype of Verticillium dahliae. However, six of these cultivars were moderately resistant. In most of the evaluated cultivars, continuous lighting allowed for the identification of resistant genotypes during a period that was 3 weeks shorter than that which is normally required in these assessments. This reduction was even greater for the resistant cultivars. The use of continuous lighting could thus be an important tool for use in olive breeding programs, where it is necessary to evaluate many genotypes in short durations and, therefore, to optimize time, space, and labor.
\end{abstract}

Andalucía is the main producing region of olive oil (Olea europaea L.) and table olives in Spain - the worldwide leading producer country (Barranco et al., 2010; IOC, 2013). Thus, any factor that affects olive tree production has a significant effect on the economy of the country. Verticillium wilt of Olive (VWO), caused by Verticillium dahliae Kleb., is currently the most destructive and threatening disease of olive in the Mediterranean region (Bubici and Cirulli, 2011; Hiemstra and Harris, 1998; López-Escudero and Mercado-Blanco, 2011; Tsror, 2011). This disease is the major problem in soils that are infested with highly virulent defoliating isolates of the pathogen, which kills a substantial number of trees annually (LópezEscudero and Mercado-Blanco, 2011). The extension of VWO has been associated with the establishment of new olive orchards in infested soils, the use of infected plant material, and the spread of highly virulent

\footnotetext{
Received for publication 10 June 2014. Accepted for publication 8 July 2014 .

This research is a portion of the thesis of Mrs. Gloria María García-Ruiz.

These studies were supported by Projects FEDERINIA: RTA 2010-00013-C02-01, RFP 2009-00008C02-01, and RFP 2012-00005; and AGL 2011-30137 of the Science and Innovation Ministry of Spain and co-financed by the EU FEDER program.

We thank the IFAPA Alameda del Obispo (Córdoba) for providing olive cultivars from the World Olive Germplasm Bank.

${ }^{1}$ To whom reprint requests should be addressed; e-mail g22garug@gmail.com.
}

and Changlot Real from Spain became highly resistant after artificial and natural infections (López-Escudero and Mercado-Blanco, 2011; Trapero et al., 2013b). Moreover, the interest in this topic has also been reflected in many studies that were conducted in the center and eastern Mediterranean Basin countries beginning in the 1970s (Cirulli and Montemurro, 1976; Paplomatas and Elena, 2001; Tjamos et al., 1985). Similarly, some countries of the eastern Mediterranean have begun evaluating the resistance of their own olive cultivars to $V$. dahliae (Al-Ahmad and Mosli, 1993; Erten and Yildiz, 2011; Levin et al., 2003; Sesli et al., 2010).

In previous studies, the resistance of olive genotypes to this disease has usually been assessed in growth chambers. However, such environmental conditions permit the evaluation of only a small number of olive cultivars in each assay (López-Escudero et al., 2004, 2007; Martos-Moreno et al., 2006) as a result of the required time and space (Trapero et al., 2013a). Nevertheless, previous studies have demonstrated that the use of greenhouses in our location (southern Spain) permits the assessment of a higher number of cultivars and could provide an alternative method to the use of growth chambers (Garcia-Ruiz et al., 2014).

The use of different lighting ranges and their influence on the plant growth have been evaluated in several studies of normally herbaceous species (Pegg and Brady, 2002). Moreover, daylength significantly affects disease development in verticillium wilts and plant resistance, reflected mainly in the levels of mycelial colonization, although some reported results are contradictory (Pegg and Brady, 2002). Therefore, in potato (Solanum tuberosum), a short-day photoperiod under field conditions is necessary for tuber formation and increases the disease level (Busch and Edgington, 1967; Tsror et al., 1990). Additionally, Pegg and Jonglaekha (1981) demonstrated that Chrysanthemum (Chrysanthemum sp.) plants that were infected with $V$. dahliae and grown under long-day conditions showed only slight wilt symptoms, whereas greater mycelial growth and more extensive stem colonization occurred when the plants were grown under reduced light conditions. In contrast, Sackston and Sheppard (1973) reported that sunflower (Helianthus annuus L.) plants developed more severe symptoms of verticillium wilt when grown under long-day than under short-day conditions.

Temperature also significantly influences the mycelial growth of the pathogen and plant colonization. $V$. dahliae has an optimal growth range of 22 to $27^{\circ} \mathrm{C}$ (Pegg and Brady, 2002), and some growth can occur even at $33{ }^{\circ} \mathrm{C}$, but no microsclerotia were found at temperatures greater than $30^{\circ} \mathrm{C}$ (Devaux and Sackston, 1966). In cotton (Gossypium sp.), the expression of resistance to a given strain of $V$. dahliae can vary with the temperature (Barrow, 1970; Bell and Presley, 1969; Xu et al., 2012), which could mask the final recorded disease severity (Garber and Presley, 1971). In tomato (Solanum lycopersicum L.), 
high temperatures and short-day conditions encourage the development of verticillium wilts in susceptible, tolerant, and resistant cultivars (Jones et al., 1978).

In olive tree, few studies investigated the olive-verticillium-temperature interaction. Indeed, experiments to determine the influence of global climate change on $V$. dahliae pathotypes and the development of the disease in olive plants exposed that, under the current $\mathrm{CO}_{2}$ concentration, optimal verticillium wilt development occurred from 20 to $24{ }^{\circ} \mathrm{C}$ and was more rapid and severe under the most favorable extremely susceptible cultivar-D pathotype combination (Lucena et al., 2013). The aim of this research work was to assess the influence of continuous and natural lighting on VWO onset and development when assessing the resistance of olive cultivars to the defoliating pathotype of Verticillium dahliae under greenhouse conditions.

\section{Materials and Methods}

Plant material and inoculation method. The own-rooted plants of 12 olive cultivars from the WOGB were used. These plants were propagated from soft-wood cuttings and were hardened for 5 months in a greenhouse under natural lighting following the methodology of Caballero and Del Río (2010) (Table 1).

The plants were inoculated with a highly virulent cotton-defoliating $V$. dahliae isolate, V117 (Blanco-López et al., 1989) following the technique of López-Escudero et al. (2004). Eight plants per cultivar were transplanted into pots of sterile black plastic that contained a combination of sterile soil with sand, lime, and peat $(1: 1: 1)$ and were placed on greenhouse benches. The cultivar Frantoio, which is resistant to $V$. dahliae infection (LópezEscudero et al., 2004), was used as the reference cultivar (resistant control).
Lighting conditions. The experiment was conducted in two greenhouses under different environmental conditions following a factorial randomized block design. Half of the blocks were located in a greenhouse with continuous lighting (CL). Inside this greenhouse, natural light was supplemented with lamps (IP65, 400 WHPS light bulbs; Secom Iluminación S.L., Murcia, Spain). The other half of the blocks was placed in another greenhouse under natural lighting (NL) conditions, which ranged between 12 and $14.8 \mathrm{~h}$ of natural light throughout the experiment. The temperature and relative humidity were measured in both of the greenhouses by measurement probes that were connected to the software Synopta 2.7.5.1 (HortiMaX B.V., Pijnacker, The Netherlands).

Disease assessment. The disease severity was assessed for 17 weeks, beginning 6 weeks after inoculation. The disease symptoms were evaluated on a scale from 0 (healthy plant or plant without symptoms) to 4 (dead plant) based on the percentage of plant tissue that was affected by chlorosis, leaf, and shoot necrosis or defoliation. The area under the disease progress curve (AUDPCP) was estimated considering its percentage with regard to the maximum possible value that could be reached in period of assessment according to the formula of Campbell and Madden (1990): $A U D P C P=$ $\left[t / 2 *\left(S_{2}+2 * S_{3}+\ldots+S_{i}\right) / 4 * n\right] * 100(\mathrm{t}=$ interval in days between observations; $S_{\mathrm{i}}=$ final mean severity; $4=$ maximum disease rating; and $n=$ number of observations from the first reading of the symptoms).

The AUDPCP was the main parameter that was used to assess the level of resistance. The final mean severity (FMS), percentage of dead plants (PDP), and disease recovery in the inoculated plants were also considered (López-Escudero and Blanco-López 2005). These values were compared with those of the resistant control 'Frantoio'. To classify the cultivars, the resistance to verticillium wilt was categorized considering the AUDPCP, FMS, and PDP values according to LópezEscudero et al. (2004, 2007). The cultivars were, therefore, classified into five resistance categories: highly resistant $(\mathrm{HR})=\mathrm{AUDPCP}$ from $0 \%$ to $10 \%$, FMS lower than 1.5 and no dead plants; resistant $(\mathrm{R})=$ AUDPCP from $11 \%$ to $30 \%$, FMS lower than 1.5 and no dead plants; moderately susceptible (MS) = AUDPCP from $31 \%$ to $50 \%$, FMS from 1.5 to 2.5 and PDP as high as $30 \%$; susceptible $(\mathrm{S})=$ AUDPCP from $51 \%$ to $70 \%$, FMS greater than 2.5, and PDP from $30 \%$ to $50 \%$; and extremely susceptible (E) = AUDPCP from $71 \%$ to $100 \%$ and FMS and PDP greater than $3.0 \%$ and $50 \%$, respectively.

To evaluate the influence of lighting during the incubation period (IP) on disease progress, the accumulated hours between 20 and $25{ }^{\circ} \mathrm{C}$ (the optimum temperature for the disease development varies between this range according to López-Escudero et al. 2004; Soesanto and Termorshuizen, 2001; $\mathrm{Xu}$ et al., 2012), and the number of accumulated light hours were measured.

The data were subjected to an analysis of variance and analyzed by a factorial design using the Statistix 9.0 program (Analytical Software, Tallahassee, FL). The mean values were compared using Fisher's protected least significant difference test at $P=0.05$.

\section{Results}

Symptoms, disease progress, and analysis of resistance. Verticillium wilt symptoms were not observed in the non-inoculated plants, which grew normally, producing new twigs from the seventh week after transplanting.

The most severe observed symptom was the defoliation of green leaves, which developed intensive and abruptly in most of plants of the cultivars Rowghani, Sorani-787,

Table 1. Final values of the phytopathological parameters that were used to assess the olive cultivars that were inoculated with a Verticillium dahliae defoliating pathotype. $^{\mathrm{z}}$

\begin{tabular}{|c|c|c|c|c|c|c|c|c|c|c|}
\hline \multirow[b]{2}{*}{ Cultivar $^{\mathrm{y}}$} & \multicolumn{3}{|c|}{ AUDPCP (\%) } & \multicolumn{3}{|c|}{ FMS } & \multicolumn{3}{|c|}{ IP } & \multirow[b]{2}{*}{ Resistance $^{\mathrm{y}}$} \\
\hline & $C L^{x}$ & NL & Mean & $\mathrm{CL}$ & NL & Mean & $\mathrm{CL}$ & NL & Mean & \\
\hline 'Rowghani' (IRN; 1139) & 65.3 & 65.8 & $65.6 \mathrm{a}$ & 4.0 & 3.8 & $3.9 \mathrm{a}$ & 7.5 & 6.0 & $6.8 \mathrm{a}$ & ES \\
\hline 'Sorani-787' (SYR; 787) & 59.2 & 61.8 & $60.5 \mathrm{a}$ & 3.9 & 4.0 & $4.0 \mathrm{a}$ & 9.0 & 10.0 & $9.5 \mathrm{abc}$ & ES \\
\hline ‘Toffahi’ (EGY; 721) & 49.1 & 59.6 & $54.3 \mathrm{a}$ & 3.5 & 3.6 & $3.6 \mathrm{a}$ & 7.8 & 6.8 & $7.3 \mathrm{ab}$ & ES \\
\hline 'Oblica' (HRV; 706) & 38.4 & 19.5 & $29.0 \mathrm{~b}$ & 3.0 & 2.1 & $2.6 \mathrm{~b}$ & 10.5 & 10.8 & $10.5 \mathrm{bc}$ & $\mathrm{S}$ \\
\hline 'Manzanilla de Lorca-808' (ESP; 808) & 34.9 & 9.2 & $20.2 \mathrm{bc}$ & 2.0 & 0.9 & $1.4 \mathrm{c}$ & 9.0 & 14.5 & $12.1 \mathrm{c}$ & MS \\
\hline 'Klon-14-1081' (ALB; 1081) & 22.6 & 8.7 & $15.7 \mathrm{bc}$ & 1.3 & 0.7 & $1.0 \mathrm{~cd}$ & 10.5 & 12.5 & $11.5 \mathrm{c}$ & MS \\
\hline ‘Wardan’ (EGY; 725) & 19.7 & 9.2 & $14.5 \mathrm{bc}$ & 1.3 & 0.4 & $0.9 \mathrm{~cd}$ & 10.8 & 12.5 & $11.6 \mathrm{c}$ & $\mathrm{R}$ \\
\hline 'Manzanilla de Lorca-809' (ESP; 809) & 17.5 & 6.0 & $12.6 \mathrm{c}$ & 1.0 & 0.7 & $0.9 \mathrm{~cd}$ & 9.5 & 14.3 & $11.6 \mathrm{c}$ & $\mathrm{R}$ \\
\hline ‘Nasuhi’ (ISR; 857) & 16.6 & 7.9 & $12.2 \mathrm{c}$ & 1.2 & 0.8 & $1.0 \mathrm{~cd}$ & 9.8 & 14.0 & $11.9 \mathrm{c}$ & $\mathrm{R}$ \\
\hline ‘Kokerrmadh Berati’ (ALB; 1080) & 13.8 & 9.8 & $11.8 \mathrm{c}$ & 1.1 & 1.1 & $1.1 \mathrm{~cd}$ & 12.0 & 13.3 & $12.6 \mathrm{c}$ & $\mathrm{R}$ \\
\hline ‘Frantoio' (ITA; 80) & 13.0 & 6.0 & $9.5 \mathrm{c}$ & 0.9 & 0.3 & $0.6 \mathrm{~d}$ & 12.0 & 14.3 & $13.2 \mathrm{c}$ & $\mathrm{R}$ \\
\hline 'Marsaline’ (TUN; 535) & 13.6 & 2.2 & $7.9 \mathrm{c}$ & 0.6 & 0.4 & $0.5 \mathrm{~cd}$ & 11.0 & 16.0 & $13.5 \mathrm{c}$ & $\mathrm{R}$ \\
\hline 'Razzola' (ITA; 177) & 15.8 & 1.0 & $7.3 \mathrm{c}$ & 1.2 & 0.2 & $0.6 \mathrm{~cd}$ & 9.3 & 16.5 & $13.4 \mathrm{c}$ & $\mathrm{R}$ \\
\hline Mean & $30.4 \mathrm{a}$ & $21.9 \mathrm{~b}$ & & $2.0 \mathrm{a}$ & $1.6 \mathrm{~b}$ & & $9.8 \mathrm{a}$ & $12.2 \mathrm{~b}$ & & \\
\hline
\end{tabular}

${ }^{\mathrm{z}} \mathrm{AUDPCP}=$ area under the disease progress curve with reference to the maximum value that was potentially reached during the assessment period; FMS $=$ final mean severity of the symptoms 17 weeks after inoculation; IP = disease incubation period. This value is the number of weeks after the inoculation in which each individual plant showed the first symptoms. The displayed value is the mean for each cultivar and lighting condition. The values in the columns and the last line followed by the same letters are not significantly different at $P=0.05$ according to Fisher's protected least significant difference test.

${ }^{\mathrm{y}}$ Name of the cultivar (country; accession number in the World Olive Germplasm Bank).

${ }^{\mathrm{x}}$ Continuous lighting conditions (CL); natural lighting conditions (NL).

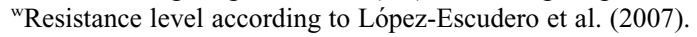


Table 2. Environmental and phytopathological parameters that were used to evaluate the influence of lighting according to the resistance level. ${ }^{\mathrm{z}}$

\begin{tabular}{|c|c|c|c|c|c|c|}
\hline Resistance level $^{\mathrm{y}}$ & Lighting $^{x}$ & $\mathrm{IP}^{\mathrm{w}}$ (weeks) & Accumulated light hoursv & Hours $\left(20 \text { to } 25^{\circ} \mathrm{C}\right)^{\mathrm{u}}$ & $\operatorname{AUDPCP}^{\mathrm{t}}(\%)$ & FMS $^{s}$ \\
\hline$\overline{\mathrm{ES}}$ & Continuous & $8.1 \mathrm{~cd}$ & $1382.0 \mathrm{bc}$ & $715.9 \mathrm{~b}$ & $57.9 \mathrm{a}$ & $3.8 \mathrm{a}$ \\
\hline S-MS & Continuous & $10.1 \mathrm{bc}$ & $1719.3 \mathrm{ab}$ & $917.3 \mathrm{ab}$ & $31.7 \mathrm{~b}$ & $2.1 \mathrm{~b}$ \\
\hline S-MS & Natural & $12.6 \mathrm{a}$ & $1214.9 \mathrm{c}$ & $796.9 \mathrm{ab}$ & $12.5 \mathrm{~cd}$ & $1.2 \mathrm{c}$ \\
\hline $\mathrm{R}$ & Natural & $14.3 \mathrm{a}$ & $1389.8 \mathrm{bc}$ & $916.5 \mathrm{a}$ & $6.3 \mathrm{~d}$ & $0.6 \mathrm{~d}$ \\
\hline
\end{tabular}

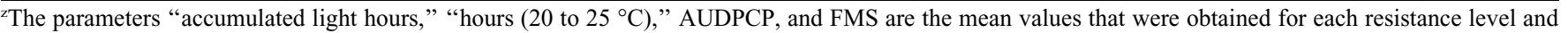
lighting condition. The values of "accumulated light hours" and "hours $\left(20\right.$ to $\left.25^{\circ} \mathrm{C}\right)$ " were calculated with respect to the incubation period (IP) of each individual plant (Table 1). The values in the columns followed by the same letters are not significantly different at $P=0.05$ according to Fisher's protected least significant difference test.

${ }^{\mathrm{y}}$ Resistance level from Table 1. The cultivars were grouped according their resistance level: extremely susceptible (ES), susceptible (S), moderately susceptible (MS), and resistant (R).

${ }^{\mathrm{x}}$ Lighting that was used in each greenhouse.

${ }^{\mathrm{w}} \mathrm{IP}=$ disease incubation period. These values are the mean values of weeks after inoculations for each group of resistance level and were calculated using the IP data of each plant.

"Number of accumulated light hours under each condition.

"Number of accumulated hours between 20 and $25^{\circ} \mathrm{C}$.

${ }^{\mathrm{t}} \mathrm{AUDPCP}=$ area under the disease progress curve with reference to the maximum value that was potentially reached during the assessment period for each group of resistance level.

${ }^{\mathrm{s}} \mathrm{FMS}$ = final mean severity of symptoms 17 weeks after inoculation for each group of resistance level.

and Toffahi, leading to plant death. However, in many other cultivars, the defoliation of green leaves was progressive and occurred partially in some shoots. Apoplexy affected the entire plant in several extremely susceptible cultivars such as 'Toffahi' and caused the progressive death of these plants. Chlorosis was frequently observed and, in resistant cultivars such as Marsaline or Razzola was only slight and temporary. The disease recovery, which is characterized by the production of new shoots and leaves after suffering slight disease symptoms, was observed in some cultivars such as Frantoio, Marsaline, and Razzola (Table 1).

'Frantoio', the resistant control, exhibited under CL conditions AUDPCP and FMS values of $13.0 \%$ and 0.9 , respectively, and no plant death (Table 1). Analyzing the phytopathological values and comparing them to the references (López-Escudero et al., 2007) under CL conditions, the cultivars Rowghani, Sorani-787, and Toffahi were extremely susceptible and significantly different from the cultivar Frantoio, exhibiting AUDPCP, FMS, and PDP values greater than $49.1 \%, 3.5$ and $75 \%$, respectively (Table 1). The susceptible cultivar Oblica exhibited an AUDPCP value of $38.4 \%$ (Table 1 ). The other group of two cultivars, Manzanilla de Lorca-808 and Klon-14-1081, were considered moderately susceptible with AUDPCP and FMS mean values of $28.8 \%$ and 1.7 , respectively (Table 1). Finally, six cultivars (Wardan, Manzanilla de Lorca-809, Nasuhi, Kokerrmadh Berati, Razzola, and Marsaline) were resistant with no plant death and AUDPCP values lower than $20 \%$. The phytopathological values of these resistant cultivars did not differ statistically from the values of cultivar Frantoio (Table 1).

Differences between the lighting conditions. The comparison between the two lighting conditions for the AUDPCP, FMS, and IP parameters showed significant differences (Table 2). These differences did not depend on the cultivar, because the lighting conditionscultivar interaction was not significant for AUDPCP $(P=0.609)$, FMS $(P=0.236)$, or

-Extremely susceptible - -Susceptible-Moderately susceptible \pm Resistant

A Continuous lighting

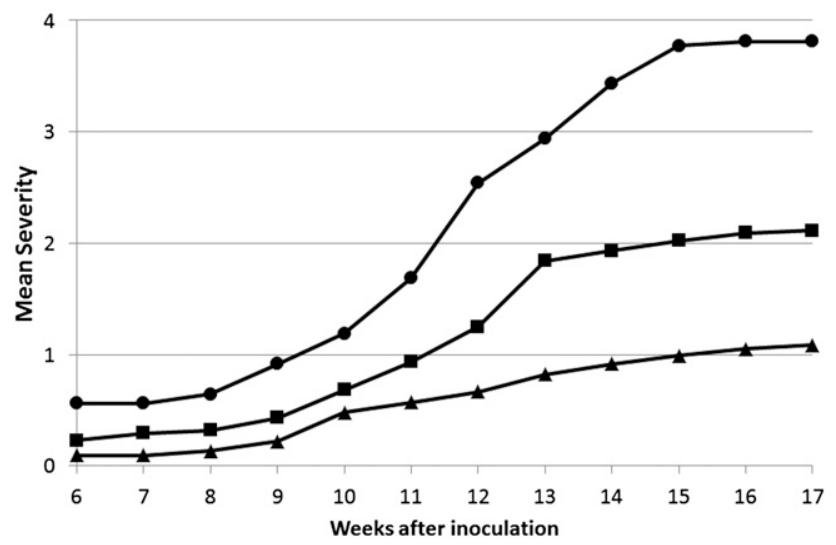

B

Natural lighting

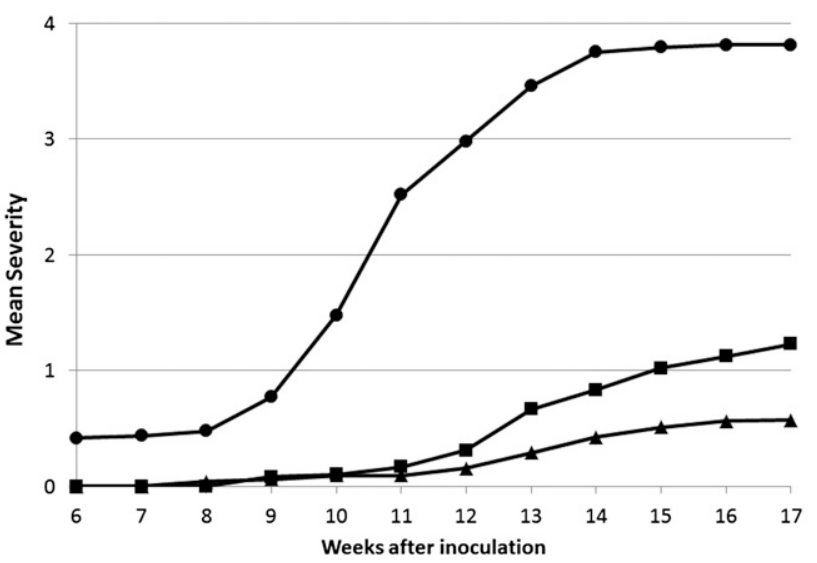

Fig. 1. Disease progress based on the symptom severity of olive cultivars after inoculation with a defoliating isolate of Verticillium dahliae under both the conditions of greenhouse with continuous lighting (A) and greenhouse with natural lighting (B). The cultivars were grouped by their resistance level (Table 1). The symptom severity was assessed weekly based on a 0 to 4 scale according to percentage of plant tissue that was affected by necrosis of the leaves and branches, chlorosis, and defoliation and rolling of leaves $(0=$ healthy plant or plant with no symptoms; $1=1 \%$ to $33 \% ; 2=34 \%$ to $66 \% ; 3=67 \%$ to $99 \%$; and $4=$ dead plant).

IP $(P=0.874)$. The disease onset occurred almost 3 weeks earlier under CL conditions than under NL conditions (Tables 1 and 2).
When the cultivars were analyzed in groups according to the calculated susceptibility level, there were significant differences in the 
phytopathological parameters between the lightning conditions in resistant, moderately susceptible, or susceptible cultivars with plants showing a higher susceptibility level under CL conditions. In contrast, no differences were found in the extremely susceptible cultivars (Table 2).

The cultivars showed significant differences for the accumulated hours between 20 and $25{ }^{\circ} \mathrm{C}$ until disease onset, whereas there were no significant differences between the lighting conditions for the same parameter. Thus, most of the cultivar groups (susceptible, moderately susceptible, and resistant) did not have differences between the conditions with the number of accumulated hours being similar (Table 2), although this fact did not apply to the group of extremely susceptible cultivars, which showed significant differences between the CL and NL conditions (Table 2). This temperature range (20 to $25^{\circ} \mathrm{C}$ ) was reached from May inside the greenhouse with NL with the cultivars exhibiting a slight delay in disease onset with respect to the CL environment (Fig. 1; Table 2).

The analysis of the parameter "accumulated light hours" revealed significant differences between the lighting conditions for each resistance group, although more light hours were required under the CL environment than under the NL environment for the development of the first disease symptoms (Table 2).

\section{Discussion}

Growth chamber conditions are more effective at producing rapid disease development and greater disease severity values than are greenhouse conditions (Garcia-Ruiz et al., 2014; Trapero et al., 2013a). However, a lower number of cultivars can be assessed in a growth chamber than in a greenhouse as a result of limited available space in the former (Trapero et al., 2013a). This experiment was performed in two greenhouses during a favorable period for disease progress under our conditions (from March to July) using lamps in one of the greenhouses to achieve continuous lighting and slightly increasing the night temperatures. Thus, throughout most of the evaluation period in the greenhouse under CL conditions, the temperature was 20 to $25^{\circ} \mathrm{C}$, which is the optimum range for $V$. dahliae infection and colonization (López-Escudero et al., 2004; Soesanto and Termorshuizen, 2001; Xu et al., 2012) with the most favorable temperature being $23.4{ }^{\circ} \mathrm{C}$ (Varo et al., 2013). Inside the greenhouse under NL conditions, the plants were specifically subjected to daily and night temperature changes that might affect infection, as revealed by the calculated accumulated hours between 20 and $25{ }^{\circ} \mathrm{C}$ (Brinkerfoff, 1973; Garber and Presley, 1971; Wilhelm and Taylor, 1965)

Many of the olive cultivars that were evaluated in this study were extremely susceptible, susceptible, or moderately susceptible, demonstrating the high susceptibility of olive cultivars to the defoliating pathotype of Verticillium dahliae (Garcia-Ruiz et al., 2014; López-Escudero and Mercado-Blanco, 2011;
Mercado-Blanco and López-Escudero, 2012). Nevertheless, the six genotypes 'Wardan', 'Manzanilla de Lorca-809', 'Nasuhi', 'Kokerrmadh Berati', 'Marsaline', and 'Razzola' were considered to be resistant to this disease, representing a high percentage (six of the 12 evaluated cultivars) compared with the findings of previous studies under growth chamber conditions and using a conidial suspension (López-Escudero et al., 2004, 2007; Martos-Moreno et al., 2006), in which this percentage was less than $6 \%$ of the total number of evaluated genotypes. This disagreement could be the result of the range of temperatures inside the greenhouses during the final assessment weeks, which likely influenced the colonization and final disease severity of the olive cultivars. This disease reduction caused by high temperatures has also been reported for cotton cultivars (Barrow, 1970; Bell and Presley, 1969; Garber and Presley, 1971; Pegg and Brady, 2002).

The number of accumulated hours between 20 and $25^{\circ} \mathrm{C}$ did not show significant differences in most of the cultivars (susceptible, moderately susceptible, and resistant) when comparing both of the environments, indicating that each plant of a fixed cultivar would need to accumulate the same number of hours at that temperature range until disease onset. Subsequently, this optimal temperature range could stimulate the development and colonization of olive cultivars by $V$. dahliae.

The environmental parameter "accumulated light hours" seems not to have a clear influence on pathogen growth by itself in the case of olive tree, although the lightingtemperature interaction could have a slight influence on disease development, like in tomato, in which high temperatures and short-day conditions stimulate pathogen colonization (Jones et al., 1978).

Therefore, the use of CL inside greenhouses could improve the onset and development of verticillium wilt disease with an advantage of almost 3 weeks at the first evidence of symptoms in cultivars with a certain level of susceptibility and more than 4 weeks in the case of resistant cultivars. This delay in the first symptoms could be the result of environmental conditions in a greenhouse under NL conditions, which had a lower mean temperature and fewer hours in the optimal temperature range than in a greenhouse under CL conditions. However, in both of these environments, the disease onset occurred at nearly the same time in the extremely susceptible cultivars, which showed similar values of FMS and AUDPCP. Thus, the lighting and temperature conditions may not influence the reaction of highly susceptible olive genotypes when the plants are inoculated with $V$. dahliae, because these plants exhibited symptoms from the seventh week after inoculation independently of the environmental conditions.

Finally, this study reports the first evidence of the resistance to VWO of six newly studied olive cultivars. Two of these cultivars, Kokerrmadh Berati and Razzola, have been recently reported as synonyms of the cultivar Frantoio after being molecularly and morphologically characterized (Trujillo et al., 2013). Although these findings narrow the availability of resistant germplasm, they also emphasize the reliability of the inoculation method. These resistant cultivars should be tested under field conditions to confirm their resistance level with the goal of including these cultivars in breeding programs as new disease-resistant cultivars or rootstocks.

\section{Literature Cited}

Al-Ahmad, M.A. and M.N. Mosli. 1993. Verticillium wilt of olive in Syria. EPPO Bul. 23:521-529.

Barranco, D., R. Fernández-Escobar, and L. Rallo. 2010. Olive growing. Junta de Andalucía, Mundi Prensa, RIRDC, AOA, Pendle Hill, Australia.

Barrow, J.R. 1970. Critical requirements for genetic expression of verticillium wilt tolerance in Acala cotton. Phytopathology 60:559-560.

Bell, A.A. and J.T. Presley. 1969. Temperature effects upon resistance and phytoalexin synthesis in cotton inoculated with Verticillium albo-atrum. Phytopathology 59:1141-1151.

Blanco-López, M.A., J. Bejarano-Alcázar, J.M. Melero-Vara, and R.M. Jiménez-Díaz. 1989. Current status of verticillium wilt of cotton in southern Spain: Pathogen variation and population in soil, p. 123-132. In: Tjamos, E.C. and C.H. Beckman (eds.). Vascular wilt diseases plants. NATO ASI Ser. H: Cell Biology, Springer-Verlag, New York, NY

Brinkerfoff, L.A. 1973. Effects of environment on the pathogen and the disease, p. 48-88. In: USDA, Publication ARS-S-19 (eds.). Verticillium wilt of cotton. Proc. Wkshp. Conf. Natl. Cotton Pathol. Res. Lab. ARS-USDA, College Station, TX

Bubici, G. and M. Cirulli. 2011. Verticillium wilt of olives, p. 191-222. In: Schena, L., G.E. Agosteo, and S.O. Cacciola (eds.). Olive diseases and disorders. Transworld Res. Network, Kerala, India.

Busch, L.V. and L.V. Edgington. 1967. Correlation of photoperiod with tuberization and susceptibility of potato to Verticillium albo-atrum. Can. J. Bot. 45:691-693.

Caballero, J.M. and C. Del Río. 2010. Propagation methods, p. 83-112. In: Barranco, D., R. Fernández-Escobar, and L. Rallo (eds.). Olive growing. Junta de Andalucía, Mundi Prensa, RIRDC, AOA, Pendle Hill, Australia.

Caballero, J.M., C. Del Río, D. Barranco, and I. Trujillo. 2006. The olive world germplasm bank of Córdoba, Spain. Olea 25:14-19.

Campbell, C.L. and L.V. Madden. 1990. Introduction to plant disease epidemiology. John Wiley and Sons, New York, NY.

Cirulli, M. and G. Montemurro. 1976. A comparison of pathogenic isolates of Verticillium dahliae and sources of resistance in olive. Agriculturae Conspectus Scientificus 39:469-476.

Devaux, A.L. and W.E. Sackston. 1966. Taxonomy of verticillium species causing wilt of horticultural crops in Quebec. Can. J. Bot. 44:803-811.

Erten, L. and M. Yildiz. 2011. Screening for resistance of Turkish olive cultivars and clonal rootstocks to verticillium wilt. Phytoparasitica 39:83-92.

Garber, R.H. and J.T. Presley. 1971. Relation of air temperature to development of verticillium wilt on cotton in field. Phytopathology 61:204-207.

García-Cabello, S., M. Pérez-Rodríguez, M.A. Blanco-López, and F.J. López-Escudero. 2012. Distribution of Verticillium dahliae 
through watering systems in widely irrigated olive growing areas in Andalucia (southern Spain). Eur. J. Plant Pathol. 133:877-885.

Garcia-Ruiz, G.M., C. Trapero, C. Del Rio, and F.J. Lopez-Escudero. 2014. Evaluation of resistance of Spanish olive cultivars to Verticillium dahliae in inoculations conducted in greenhouse. Phytoparasitica 42:205-212.

Hiemstra, J.A. and D.C. Harris. 1998. A compendium of verticillium wilt in tree species. Ponsen \& Looijen, Wageningen, The Netherlands.

IOC. 2013. Statistics on production, imports, exports and consumption of olive oil and table olive. International Olive Council.

Jones, J.P., A.J. Overman, and P. Crill. 1978. Effect of temperature and short day on development of verticillium wilt of susceptible, tolerant and resistant tomato cultivars. Proc. Florida State Hort. Soc. 90:397-399.

Levin, A.G., S. Lavee, and L. Tsror. 2003. Epidemiology and effects of verticillium wilt on yield of olive trees (cvs. Barnea and Souri) irrigated with saline water in Israel. Phytoparasitica 31:333-343.

López-Escudero, F.J. and M.A. Blanco-López. 2005. Recovery of young olive trees from Verticillium dahliae. Eur. J. Plant Pathol. 113:367-375.

López-Escudero, F.J., M.A. Blanco-López, C. Del Río Rincón, and J.M. Caballero Reig. 2007. Response of olive cultivars to stem puncture inoculation with a defoliating pathotype of Verticillium dahliae. HortScience 42:294-298.

López-Escudero, F.J., C. Del Río, J.M. Caballero, and M.A. Blanco-López. 2004. Evaluation of olive cultivars for resistance to Verticillium dahliae. Eur. J. Plant Pathol. 110:79-85.

López-Escudero, F.J. and J. Mercado-Blanco. 2011. Verticillium wilt of olive: A case study to implement an integrated strategy to control a soil-borne pathogen. Plant Soil 344:1-50.

Lucena, C., J.L. Trapero-Casas, E. Remesal, and J.A. Navas-Cortés. 2013. Verticillium dahliae pathotypes and olive cultivars determine geographic distribution and development of verticillium wilt under current and future climate change scenarios in Southern Spain, p. 64. In: 11th Intl. Verticillium Symp., Georg-AugustUniversität, Göttingen, Germany.

Martos-Moreno, C., F.J. López-Escudero, and M.A. Blanco-López. 2006. Resistance of olive cultivars to the defoliating pathotype of Verticillium dahliae. HortScience 41:1313-1316.

Mercado-Blanco, J. and F.J. López-Escudero. 2012. Verticillium wilt of olive and its control: The heat is on. Plant Soil 355:17-21.

Paplomatas, E.J. and K. Elena. 2001. Reaction of Greek olive cultivars to the cotton defoliating strain of Verticillium dahliae, p. 51. In: 8th Intl. Verticillium Symp., Córdoba, Spain.

Pegg, G.F. and B.L. Brady. 2002. Verticillium wilts. CABI Publishing, New York, NY.

Pegg, G.F. and N. Jonglaekha. 1981. Assessment of colonization in chrysanthemum grown under different photoperiods and infected with Verticillium dahliae. Trans. Brit. Mycol. Soc. 76:353-360.

Sackston, W.E. and J.W. Sheppard. 1973. Effect of day length on reaction of sunflowers to verticillium wilt. Can. J. Bot. 51:23-26.

Sesli, M., E. Onan, S. Oden, H. Yener, and E.D. Yegenoglu. 2010. Resistance of olive cultivars to Verticillium dahliae. Sci. Res. Essays 5:1561-1565.

Soesanto, L. and A.J. Termorshuizen. 2001. Effect of temperature on the formation of microsclerotia of Verticillium dahliae. J. Phytopathol. 149:685-691.

Tjamos, E.C. 1993. Prospects and strategies in controlling verticillium wilt of olive. EPPO Bul. 23:505-512.

Tjamos, E.C., D.A. Biris, and C.C. Thanassoulopoulos. 1985. Resistance evaluation to Verticillium dahliae of olive rootstocks, p. 18-19. In: 3rd Natl. Phytopathol. Conf., Hellenic Phytopathol. Soc., Greece.
Trapero, C., C.M. Díez, L. Rallo, D. Barranco, and F.J. López-Escudero. 2013a. Effective inoculation methods to screen for resistance to verticillium wilt in olive. Sci. Hort. 162:252-259.

Trapero, C., N. Serrano, O. Arquero, A. Trapero, and F.J. López-Escudero. 2013b. Field resistance to verticillium wilt in selected olive cultivars grown in two naturally infested soils. Plant Dis. 97:668-674.

Trapero, C., L.F. Roca, E. Alcántara, and F.J. López-Escudero. 2011. Colonization of olive inflorescences by Verticillium dahliae and its significance for pathogen spread. J. Phytopathol. 159:638-640.

Trujillo, I., M.A. Ojeda, N.M. Urdiroz, D. Potter, D. Barranco, L. Rallo, and C.M. Diez. 2013. Identification of the Worldwide Olive Germplasm Bank of Córdoba (Spain) using SSR and morphological markers. Tree Genet. Genomes 10:141-155.

Tsror, L. 2011. Epidemiology and control of verticillium wilt on olive. Isr. J. Plant Sci. 59:59-69.

Tsror, L., L. Livescu, and A. Nachmias. 1990. Effect of light duration and growth season on verticillium wilt in potato. Phytoparasitica 18:331-339.

Varo, A., M.C. Raya, L. Roca, and A. Trapero. 2013. Production of microsclerotia of Verticillium dahliae to an effective method of inoculation of plants, p. 123. In: 11th Intl. Verticillium Symp., Georg-August-Universität, Göttingen, Germany.

Wilhelm, S. and J.B. Taylor. 1965. Control of verticillium wilt of olive through natural recovery and resistance. Phytopathology 55:310-316.

Xu, F., L. Yang, J. Zhang, X. Guo, X. Zhang, and G. Li. 2012. Effect of temperature on conidial germination, mycelial growth and aggressiveness of the defoliating and nondefoliating pathotypes of Verticillium dahliae from cotton in China. Phytoparasitica 40:319-327. 